\title{
Agihan Kualitas Air Kali Surabaya Berdasarkan Perbedaan Penggunaan Lahan
}

\author{
Yulfiah $^{1, *}$, Ferry Suzantho ${ }^{2}$, Maritha Nilam Kusuma ${ }^{3}$ \\ 1,2,3 Teknik Lingkungan, Institut Teknologi Adhi Tama Surabaya \\ Jl. Arief Rachman Hakim 100 Surabaya \\ *Koresponden email: yulfiah@itats.ac.id
}

Diterima : 25 Februari 2019

Disetujui : 15 Maret 2019

\begin{abstract}
Surabaya River is very beneficial to Surabaya people as its water becomes the main source of PDAM (Perusahaan Dae-rah Air Minum of Regional Water Utility Company). The existing indications on pollution in the flow of Surabaya River due to various activities at its riverbank must not be ignored. Therefore, a study on identifying the distribution of water quality of Surabaya River is required so as to be a reference for formulating control actions to river damage. Identification on water quality distribution was carried out based on the differences of land-use around the left and right sides of river. The research involved the variables of the qualities of river water and waste water thrown into the river, river characteris-tics, and land-use. The results of research demonstrated that the upstream water quality of Surabaya River was relatively better than the downstream. This statement was proven by the humans' activities which were more intensively carried out at the downstream area. Numerous land-uses and great number of people living at the riverbank became the phenomena increasing pressures toward the decreasing quality of river water.
\end{abstract}

Keywords: Surabaya River, water quality, river characteristics, distribution, land-use difference

\begin{abstract}
Abstrak
Kali Surabaya sangat besar manfaatnya bagi masyarakat Kota Surabaya, khususnya karena air Kali Surabaya merupa-kan air baku utama bagi PDAM. Adanya indikasi telah terjadi pencemaran dalam aliran Kali Surabaya oleh beragam kegiatan di bantarannya, tentu saja tidak bisa dibiarkan berlanjut. Oleh karena itu, dibutuhkan penelitian untuk men-gidentifikasi agihan kualitas air Kali Surabaya sebagai bahan acuan merumuskan tindakan pengendalian kerusakan sungai. Identifikasi agihan kualitas air dilakukan berdasarkan perbedaan penggunaan lahan yang ada di kiri kanan sungai. Variabel penelitian meliputi kualitas air sungai dan air limbah yang dibuang ke sungai, variabel karakteristik sungai, dan variabel penggunaan lahan. Hasil penelitian memberikan gambaran bahwa kualitas air Kali Surabaya di ba-gian hulu masih relatif baik dibandingkan di kawasan hilir. Pernyataan ini dikuatkan oleh kenyataan bahwa, tekanan aktifitas manusia lebih intensif di bagian hilir. Beragamnya jenis penggunaan lahan dan besarnya jumlah masyarakat yang tinggal di bantaran Kali Surabaya adalah diantara fenomena yang memperbesar tekanan terhadap penurunan kualitas air sungai.
\end{abstract}

Kata kunci: Kali Surabaya, kualitas air, karakteristik sungai, agihan, perbedaan penggunaan lahan.

\section{Pendahuluan}

Kali Surabaya merupakan sungai utama yang melintasi Kota Surabaya. Pada Dam Jagir, Kali Surabaya membelah menjadi Kali Mas yang mengalir ke arah utara kota, serta Kali Wonokromo yang mengalir ke arah timur kota. Kali Surabaya mengalir dari Dam Mlirip Mojokerto sampai Dam Jagir Surabaya dengan panjang total $41 \mathrm{~km}$. Tiga anak sungai yang bermuara di Kali Surabaya adalah Kali Kedung Sumur, Kali Marmoyo, dan Kali Kedurus. Kali Kedung Sumur menerima air dari area seluas $99 \mathrm{~km}^{2}$. Kali Marmoyo meliputi catchment area seluas $300 \mathrm{~km}^{2}$. Pada bagian atas Kali Marmoyo terdapat saluran irigasi Kubuk dan Mernung dengan catchment area seluas $28 \mathrm{~km}^{2}$ dan $155 \mathrm{~km}^{2}$. Kali Kedurus bermuara di Kali Surabaya pada Dam Gunung Sari dan menerima air dari area seluas $71 \mathrm{~km}^{2}$.

Masyarakat Kota Surabaya dan Sidoarjo sangat tergantung pada keberadaan Kali Surabaya. Hal ini disebabkan, Kali Surabaya merupakan pemasok 
utama sumber air baku PDAM Kota Surabaya dan Sidoarjo. Kapasitas produksi PDAM Kota Surabaya saja, saat ini telah mencapai 10.830 lt/dt. Kapasitas dicapai dari hasil produksi instalasi Ngagel I, II, dan III sebesar 4.250 lt/dt, instalasi Karangpilang I, II, dan III sebesar $5.950 \mathrm{lt} / \mathrm{dt}$, sumber Umbulan sebesar 110 lt/dt, serta sumber Pandaan dan lain-lain sebesar 220 lt/dt. Demikian besarnya kapasitas produksi air bersih PDAM ini, tentu saja sangat tergantung pada debit dan kualitas air Kali Surabaya.

Terlebih lagi, Kali Surabaya juga memberikan manfaat besar bagi masyarakat yang tinggal di bantarannya, termasuk masyarakat industri. Hampir semua industri yang beroperasi di bantaran Kali Surabaya memanfaatkan air Kali Surabaya sebagai salah satu komponen proses produksi. Di sisi lain, Kali Surabaya juga merupakan tempat pembuangan air limbah dari masyarakat yang hidup di bantarannya, tidak terkecuali limbah industri. Kali Surabaya merupakan tempat buangan murah meriah, khususnya bagi industri yang tidak dilengkapi fasilitas pengolah limbah memadai.

Berdasarkan nilai penting keberadaan Kali Surabaya tersebut, maka kegiatan penelitian untuk mengidentifikasi agihan kualitas air Kali Surabaya berdasarkan perbedaan penggunaan lahan di bantarannya menjadi krusial. Hasil penelitian dimanfaatkan sebagai bahan acuan merumuskan tindakan pengendalian kerusakan sungai.

\section{Tinjauan Pustaka}

Sumber air tawar di bumi berupa air permukaan (surface water) dan air tanah (groundwater). Air permukaan dapat berasal dari air tanah atau disebut sebagai aliran dasar. Sebaliknya, air tanah juga dapat berasal dari aliran air permukaan. Gejala interaksi demikian dipengaruhi gradient hydraulic. Air permukaan terklasifikasi atas badan air tergenang (standing water) dan badan air mengalir (flowing water). Diantara ragam badan air tergenang adalah danau, rawa, kolam, waduk dan sebagainya. Sementara sungai merupakan bentuk badan air mengalir.

Air sungai berbeda dengan jenis air permukaan yang lain, karena cirinya yang mengalir dengan arus searah pada kecepatan 0,1 - $1 \mathrm{~m} / \mathrm{dt}$. Kecepatan arus sungai dipengaruhi waktu, iklim, dan pola drainase. Pada sungai, biasanya terjadi percampuran masa air secara menyeluruh dan tidak terbentuk stratifikasi vertikal kolom air seperti pada danau. Kecepatan arus, erosi dan sedimentasi merupakan fenomena yang biasa terjadi di sungai. Kecepatan arus sungai dipengaruhi landscape, jenis batuan dasar, dan curah hujan. Makin rumit landscape, makin besar ukuran batuan dasar, dan makin besar curah hujan, maka kecepatan arus sungai juga semakin besar. Sedimen penyusun dasar sungai memiliki ukuran bervariasi. Perbedaan jenis sedimen dasar mempengaruhi karakteristik kualitas air sungai, pergerakan air, dan porositas dasar sungai (Effendie, H, 2003).

Kualitas air sungai merupakan perpaduan kualitas air yang masuk ke dalam aliran sungai, dengan kualitas air hasil reaksi sungai dengan mineral batuan yang dilewatinya. Kualitas air sungai merupakan sebuah sistem yang terdiri dari tiga sub sistem. Material yang dilalui air sungai, berupa macam tanah dan batuan yang tergantung pada pola ruang dan komposisi kimia merupakan sub sistem pertama. Sub sistem kedua berupa macam aliran, yaitu aliran laminer dan turbulen. Sub sistem ketiga yaitu proses perubahan, baik perubahan fisik, kimia, biologi, atau semua proses yang mengakibatkan perubahan kualitas air.

Zat kimia dalam air sungai tidak hanya berasal dari limbah. Litologi di daerah aliran sungai juga merupakan sumber zat kimia air sungai. Selain itu, air hujan juga merupakan sumber zat kimia cukup berarti bagi air sungai. Secara garis besar, polutan air sungai diklasifikasikan berdasarkan tiga hal berikut. Pertama, perbedaan lokasi sumber polutan, yaitu sumber titik dan sumber non titik. Kedua, sejarah pembentukan sungai. Ketiga berupa macam polutan, yaitu polutan organik, polutan mudah menguap atau volatile, polutan berbahan dasar netral, serta polutan berbahan dasar asam (Ward dan Robinson, 1990).

Penyebaran polutan air sungai dari sumber titik berkurang sejalan pergerakan polutan menjauhi sumbernya sesuai kemampuan self purification sungai. Self purification dapat berlangsung selama belum melampaui batas kemampuan sungai untuk melakukan proses pemurnian secara alami. Proses pemurnian tergantung waktu, jarak, jenis polutan, dan kondisi fisik sungai (Domenico dan Schwartz, 1990). Self purification juga ditentukan oleh faktor kuantitas aliran, waktu, perjalanan aliran ke hilir, temperatur air, dan aerasi. Proses pemurnian melibatkan mekanisme penyaringan atau filtration, penyerapan atau sorption, proses kimia, dekomposisi, dan pengenceran atau dilution.

Huub J. Gijzen (2006) menyampaikan bahwa Urban Water Management (UWM) harus dipertimbangkan dalam konteks pembangunan berkelanjutan. Ini berarti, pendekatan holistik harus diikuti, di mana pengelolaan layanan air perkotaan terkait dengan sumber daya air secara keseluruhan. Pengelolaan tidak hanya secara eksklusif fokus pada pendekatan ujung pipa (end pipe), sehingga menjadi sangat mahal dan tidak efektif. Dengan pendekatan 
UWM ditawarkan tiga langkah strategis, yaitu 1) pencegahan dan minimisasi polusi, 2) pemulihan agar dapat dipergunakan kembali, dan 3) mensimulasikan kapasitas self purification dari lingkungan penerima. Oleh karena itu, perlu diupayakan memaksimalkan proses alami untuk pengelolaan sumber daya air perkotaan secara efektif (kualitas air), penyediaan air dan layanan sanitasi, serta siklus air kota secara keseluruhan (kuantitas air).

Guna memperluas wawasan terkait tema penelitian, telah dipelajari sejumlah penelitian dengan topik terkait. Berikut disampaikan sejumlah penelitian yang dimaksud. Penelitian pertama yang dipelajari, dilakukan Rafaela Laino-Guanes, Mario Gonza'lez-Espinosa, Neptalı' Ramı'rez-Marcial, (2016). Penelitian berhasil menunjukkan bahwa secara garis besar nilai parameter air sungai lebih tinggi selama musim kemarau (nilai oksigen terlarut lebih tinggi, sementara nilai total padatan terlarut, total padatan tersuspensi, total fosfor, COD, dan suhu lebih rendah). Kondisi air sungai berhubungan positif dengan tutupan hutan dan perlindungan hutan. Kedua variabel ini menjadi penting dalam menjaga keamanan air bagi masyarakat. Ancaman utama terhadap air dan kualitasnya, disebutkannya sejalan dengan tekanan manusia dan pembuangan air limbah yang tidak diolah. Penelitian dilaksanakan di enam daerah tangkapan air yang terletak di DAS Grijalva bagian atas, pada kawasan perbatasan Guatemala dan Meksiko.

Penelitian berikutnya adalah penelitian yang dikerjakan oleh Yan Lu, Hongwen Xu, Yuexiang Wang, dan Yang Yang (2017). Penelitian dilaksanakan di Kota Huai'an, pada DAS Huaihe. Penelitian ditujukan untuk menghitung daya dukung lingkungan air Sungai dari tahun 2005 hingga 2014, dengan menggunakan metode analytic hierarchy process (AHP). Hasil penelitian menunjukkan bahwa, faktor sosial memiliki dampak signifikan terhadap daya dukung lingkungan air, dan perubahannya pun relatif konsisten. Total populasi dan tingkat urbanisasi merupakan bentuk tekanan utama terhadap daya dukung lingkungan air di Kota Huai'an.

Investigasi kualitas air dilakukan di Dionosoyiet (Victoria basin, Kenya) oleh Herbert John Bavor dan Michael Waters (2016). Pemodelan hidrologi dan kualitas air dilakukan berdasarkan model CRC FE POND. Model ini diadaptasi untuk menggabungkan modul limpasan curah hujan berdasarkan teknik histogram isochronal dan sebagian prediksi stokastik kualitas air (TSS, TN dan TP) berdasarkan laju aliran masuk. Dengan menggunakan data yang dikumpulkan dari Juni 2004 hingga April 2005 dan data iklim sebelumnya, pemodelan dilakukan pada periode waktu 11 tahun, yaitu dari Januari 1994 hingga Desember 2004. Ditunjukkan bahwa Victoria basin mampu menurunkan 43\% TSS, 41\% TP dan 20\% TN dengan rata-rata tingkat penurunan $21,3 \mathrm{TSS}, 0,038$ $\mathrm{TP}$, dan 1,03 TN (kg/ha/hari). Temuan penelitian memperlihatkan, selain menjadi pusat kegiatan masyarakat kota, Victoria basin telah melakukan fungsi signifikan untuk peningkatan kualitas air. Pelestarian Dionosoyiet menjadi penting dalam memastikan pemanfaatan sumber daya air secara berkelanjutan di Victoria Basin.

TA Ayandiran, OO Fawole, dan SO Dahunsi (2017) melakukan penelitian yang ditujukan untuk membangun database kualitas air di Sungai Oluwa, South Western Nigeria, dari bulan April 2011 hingga Maret 2012. Hasil penelitian menunjukkan bahwa semua parameter fisik belum melampaui Nigeria Standard Industry (NIS) untuk air minum. Hasil penelitian juga memperlihatkan bahwa semua logam berat, telah melampaui level yang diizinkan NIS dan standar WHO untuk air minum. Semua parameter kimia yang diteliti selama musim kemarau sangat berbeda dari musim hujan, kecuali untuk BOD.

Pada tahun 2017, Nidhi Gupta, Pankaj Pandey, dan Jakir Hussain melaksanakan penelitian di Sungai Narmada, negara bagian Madhya Pradesh. Hasil penelitian menemukan bahwa pada musim panas dan musim dingin, kualitas air sangat baik. Sementara kualitas buruk atau tidak cocok untuk dikonsumsi terjadi pada musim monsun. Penurunan kualitas air di musim hujan disebabkan oleh buruknya sanitasi, aliran turbulen, erosi tanah, dan aktivitas antropogenik yang cukup tinggi.

Penelitian lain dilaksanakan oleh Richa Bhardwaj, Anshu Gupta, dan J.K. Garg (2017). Tujuan penelitian adalah untuk menyelidiki pencemaran logam berat di Sungai Yamuna, Delhi. Penelitian dilakukan pada bulan Desember 2013 - Agustus 2015. Hasil penelitian memperlihatkan bahwa, konsentrasi ratarata keseluruhan logam berat secara berurutan adalah $\mathrm{Fe}>\mathrm{Cu}>\mathrm{Zn}>\mathrm{Ni}>\mathrm{Cr}>\mathrm{Pb}>\mathrm{Cd}$. Hasil studi juga menunjukkan, saluran pembuangan Najafgarh dan Shahdara sebagai dua sumber potensial yang bertanggung jawab atas kontaminasi logam berat di sungai Yamuna.

Kamran Zeinalzadeha dan Elnaz Rezaeib (2017) melaksanakan penelitian di Sungai Shahr Chai, Danau Urmia, Iran. Parameter kualitas air diukur setiap bulan dari enam aliran sungai yang dipengaruhi buangan pusat rekreasi dan aktifitas pertanian. Penelitian ditujukan untuk menyelidiki kemampuan teknik Principal Component Analysis (PCA) dalam 
mengidentifikasi dampak lingkungan dari berbagai kegiatan. Kesimpulan penelitian memperlihatkan bahwa teknik PCA pada lansekap berbeda, kualitas air di hilir sungai mengalami penurunan kualitas.

Pada tahun 2014, Edyta Kiedrzyn 'ska, Marcin Kiedrzyn 'ski, Magdalena Urbaniak, dkk, mempublikasikan hasil penelitiannya dalam jurnal Ecological Engineering. Disampaikan bahwa penelitian berupaya mengkuantifikasi transfer nutrisi pada DAS Pilica (Polandia Tengah). Penelitian juga ditujukan untuk mengevaluasi pengaruh IPAL pada eutrofikasi Sungai Pilica dan Laut Baltik. Hasil penelitian memperlihatkan bahwa, rata-rata total fosfor (TP) dan total nitrogen (TN) yang dikeluarkan dari DAS Pilica, dua dan tiga kali lebih tinggi dibandingkan dengan beban rata-rata tahunan di wilayah Polandia dan Negara Baltik. Solusi yang ditawarkan dari hasil penelitian adalah, untuk perencanaan dan pengelolaan berkelanjutan DAS harus didasarkan pada konsep ekohidrologi dan rekayasa ekologi.

Penelitian Carolien Kroeze, Silke Gabbert, Nynke Hofstra,dkk (2016), memberikan contoh representatif dari sebuah model matematika untuk mensimulasikan aliran polutan dari darat ke laut pada skala global. Pendekatan pemodelan multi-polutan digunakan untuk memahami dan mengelola permasalahan kualitas air. Polutan seringkali berasal dari banyak sumber dengan dampak beragam. Pada sisi lain, model spasial yang ada, umumnya fokus pada satu jenis polutan. Diperlukan suatu model baru yang mampu menganalisis gabungan polutan yang berpengaruh pada air permukaan. Model semacam itu dapat berfungsi sebagai dasar untuk penilaian kuantitas dan kualitas air secara terintegrasi.

\section{Metode Penelitian}

Metode yang digunakan dalam penelitian ini adalah deskriptif komparatif. Uraian sistematis dan akurat dilakukan terhadap fakta serta sifat obyek penelitian. Selanjutnya dilaksanakan kajian komparatif untuk memahami keterkaitan diantara fakta yang ada.

Pengumpulan data dilakukan melalui pengukuran karakteristik sungai secara langsung di lapangan untuk mendapatkan nilai dimensi sungai, kecepatan aliran, dan debit aliran. Sementara analisis laboratorium untuk mendapatkan data primer kualitas air, dilakukan pada 24 sampel air sungai dan 8 sampel air limbah. Sampel air dikumpulkan dari 12 stasiun pengambilan sampel dalam dua musim. Pada masing-masing stasiun dikumpulkan satu sampel air sungai pada akhir musim hujan dan satu sampel air sungai pada puncak musim kemarau, atau secara keseluruhan berjumlah 24 sampel.

Sampel air limbah hanya dikumpulkan pada empat
Tabel 1. Kualitas air kali Surabaya akhir musim hujan

\begin{tabular}{|c|c|c|c|c|}
\hline No & Nama Stasiun & $\begin{array}{l}\text { Suhu } \\
\left({ }^{0} \mathrm{C}\right)\end{array}$ & $\begin{array}{l}\text { BOD } \\
(\mathrm{mg} / \mathrm{l})\end{array}$ & $\begin{array}{c}\text { DO } \\
(\mathrm{mg} / \mathrm{l})\end{array}$ \\
\hline 1 & Jetis (Mlirip) & 30,8 & 3,3 & 6,65 \\
\hline 2 & Kali Anyar & 32,2 & 9,4 & 4,00 \\
\hline 3 & Kali Marmoyo & 30,0 & 3,6 & 4,25 \\
\hline 4 & Perning & 30,1 & 3,1 & 5,44 \\
\hline 5 & Sumber Rame & 31,3 & 1,8 & 5,53 \\
\hline 6 & $\begin{array}{l}\text { Legundi (Kali } \\
\text { Swaloyo) }\end{array}$ & 29,8 & 2,4 & 5,28 \\
\hline 7 & Driyorejo & 33,0 & 5,6 & 4,59 \\
\hline 8 & Muara Kali Tengah & 30,7 & 3,9 & 3,26 \\
\hline 9 & Karang Pilang & 29,1 & 28,1 & 2,14 \\
\hline 10 & Pagesangan & 28,7 & 4 & 1,67 \\
\hline 11 & Gunungsari & 28,3 & 2,1 & 0,94 \\
\hline 12 & Joyoboyo & 28,5 & 3,0 & 1,61 \\
\hline
\end{tabular}

stasiun pengambilan sampel. Masing-masing sampel dikumpulkan di akhir musim hujan dan puncak musim kemarau atau total berjumlah 8 sampel. Parameter kualitas air yang diukur adalah suhu, BOD, dan DO. Data primer kualitas air juga diperbandingkan dengan data sekunder hasil pemantauan rutin kualitas air secara offline yang dilakukan oleh Perum Jasa Tirta I Malang.

\section{Hasil dan Pembahasan}

Hasil pengukuran penelitian menunjukkan beberapa fakta berikut. Pengukuran di akhir musim hujan menunjukkan, kecepatan rata-rata aliran Kali Surabaya di bagian hulu relatif besar dibandingkan di bagian hilir, dengan nilai kecepatan maksimum mencapai 112,35 cm/dt. Kecepatan rata-rata menurun sejalan dengan menyempitnya luasan badan sungai dan berubahnya arah aliran menjadi bergerak lurus di bagian hilir, dari awalnya berkelok di bagian hulu. Penurunan kecepatan rata-rata aliran di bagian hilir diantaranya disebabkan oleh keberadaan tanaman enceng gondok yang menyebabkan aliran terhambat. Selanjutnya, debit rata-rata maksimum Kali Surabaya dijumpai pada stasiun Gunung Sari.

Pada pengukuran di akhir musim hujan ditunjukkan bahwa nilai BOD air sungai pada semua stasiun pengukuran nilainya masih berada di bawah baku mutu, kecuali pada stasiun Kali Anyar dan stasiun Karang pilang. Hasil pengukuran juga memperlihatkan terjadinya penurunan nilai DO dari hulu ke hilir Kali Surabaya, meskipun tidak selalu runtut. Pada daerah

Tabel 2. Kualitas air limbah di akhir musim hujan

\begin{tabular}{clrrr} 
No & Nama Stasiun & \multicolumn{1}{c}{$\begin{array}{c}\text { Suhu } \\
\text { ('C) }\end{array}$} & $\begin{array}{c}\text { BOD } \\
\text { (mg/l) }\end{array}$ & \multicolumn{1}{c}{$\begin{array}{c}\text { DO } \\
(\mathbf{m g} / \mathbf{l})\end{array}$} \\
\hline 1 & Alu Aksara & 31,9 & 34,6 & 1,75 \\
2 & Sumber Rame & 30,4 & 250,6 & 5,63 \\
3 & Driyorejo & 32,9 & 10,6 & 0,55 \\
4 & Kali Tengah & 32,9 & 25,6 & 0,29 \\
\hline
\end{tabular}


Tabel 3. Kualitas air Kali Surabaya di puncak musim kemarau

\begin{tabular}{clrrr}
\hline No & Nama Stasiun & $\begin{array}{c}\text { Suhu } \\
\mathbf{(} \mathbf{C})\end{array}$ & $\begin{array}{c}\text { BOD } \\
(\mathbf{m g} / \mathbf{l})\end{array}$ & \multicolumn{1}{c}{$\begin{array}{c}\text { DO } \\
(\mathbf{m g} / \mathbf{l})\end{array}$} \\
\hline 1 & Jetis (Mlirip) & 28,7 & 4,4 & 7,38 \\
2 & Kali Anyar & 28,4 & 3,6 & 5,14 \\
3 & Kali Marmoyo & 30,8 & 13,2 & 3,06 \\
4 & Perning & 29,8 & 19,0 & 7,32 \\
5 & Sumber Rame & 30,5 & 5,2 & 7,10 \\
6 & Legundi (Kali & 27,5 & 4,2 & 6,58 \\
& Swaloyo) & & & \\
7 & Driyorejo & 29,2 & 6,3 & 5,88 \\
8 & Muara Kali Tengah & 28,5 & 6,8 & 3,55 \\
9 & Karang Pilang & 26,6 & - & 2,81 \\
10 & Pagesangan & 26,6 & 5,4 & 1,84 \\
11 & Gunungsari & 27,5 & 7,6 & 0,39 \\
12 & Joyoboyo & 27,0 & 9,7 & 1,90 \\
\hline
\end{tabular}

hulu nilai DO relatif baik, yaitu lebih dari 5. Dengan demikian dapat disampaikan bahwa ekosistem Kali Surabaya di bagian hulu masih relatif lebih baik jika dibandingkan dengan di bagian hilir. Pernyataan ini dikuatkan oleh hasil observasi lapangan yang memperlihatkan adanya tekanan aktifitas kegiatan masyarakat terhadap Kali Surabaya di bagian hilir secara lebih intensif. Beragamnya jenis penggunaan lahan dan tingginya jumlah masyarakat yang tinggal di bagian hilir Kali Surabaya adalah fenomena yang menunjukkan besarnya tekanan terhadap kualitas air Kali Surabaya bagian hilir.

Pada pengukuran di puncak musim kemarau dijumpai fenomena bahwa rata-rata kecepatan aliran sungai mencapai $63,99 \mathrm{~cm} / \mathrm{dt}$ dengan debit ratarata mencapai $23,18 \mathrm{~m}^{3} / \mathrm{dt}$. Rata-rata debit tertinggi dijumpai pada stasiun Muara Kali Tengah, dan terendah di stasiun Kali Anyar.

Rata-rata BOD hasil pengukuran di puncak musim kemarau, pada stasiun pengukuran Kali Marmoyo, Perning, Gunung Sari, dan Joyoboyo, nilainya telah melampuai batas baku mutu. Sementara, nilai DO rata-rata masih menunjukkan bahwa pada bagian hulu Kali Surabaya nilainya masih relatif lebih baik dibandingkan pada bagian hulu sungai.

Data sekunder menunjukkan, debit rata-rata pada stasiun pengukuran di pintu air Mlirip mencapai 20,07 $\mathrm{m}^{3} / \mathrm{dt}$. Sementara rata-rata debit di stasiun pengukuran Gunung Sari dan Perning, masing-masing mencapai

Tabel 4. Kualitas air Limbah di puncak musim kemarau

\begin{tabular}{llcrr}
\hline No & Nama Stasiun & \multicolumn{1}{c}{$\begin{array}{c}\text { Suhu } \\
\left(\mathbf{C}^{\mathbf{C}} \mathbf{C}\right)\end{array}$} & $\begin{array}{c}\text { BOD } \\
(\mathbf{m g} / \mathbf{l})\end{array}$ & \multicolumn{1}{c}{$\begin{array}{c}\text { DO } \\
(\mathbf{m g} / \mathbf{l})\end{array}$} \\
\hline 1 & Alu Aksara & 28,1 & 406,0 & 0,27 \\
2 & Sumber Rame & 30,0 & 3,8 & 6,82 \\
3 & Driyorejo & 31,6 & 26,0 & 2,62 \\
4 & Kali Tengah & 30,7 & 265,5 & 0,32 \\
\hline
\end{tabular}

Tabel 5. Data sekunder rata-rata kualitas air Kali Surabaya

\begin{tabular}{llrr}
\hline No & Lokasi Pengukuran & $\begin{array}{c}\text { BOD } \\
(\mathrm{ppm})\end{array}$ & DO (ppm) \\
\hline 1 & Canggu & 3,17 & 5,72 \\
2 & Perning & 2,97 & 5,07 \\
3 & Jrebeng & 4,62 & 4,53 \\
4 & Cangkir & 4,77 & 4,28 \\
5 & Bambe & 7,37 & 3,35 \\
6 & Karang Pilang & 6,32 & 3,08 \\
7 & Sepanjang & 5,48 & 2,72 \\
8 & Gunung Sari & 4,30 & 2,87 \\
9 & Ngagel / Jagir & 16,10 & 2,18 \\
\hline
\end{tabular}

$26,01 \mathrm{~m}^{3} / \mathrm{dt}$ dan $43,96 \mathrm{~m}^{3} / \mathrm{dt}$. Hasil pengukuran debit Kali Surabaya di akhir musim hujan menunjukkan nilai $23 \mathrm{~m}^{3} / \mathrm{dt}$. Atau secara garis besar, rata-rata debit Kali Surabaya berada dalam kisaran $20 \mathrm{~m}^{3} / \mathrm{dt}$ sampai dengan $50 \mathrm{~m}^{3} / \mathrm{dt}$.

Seperti halnya hasil penelitian, maka data sekunder (Basis Data Pengelolaan Lingkungan Hidup tahun 2006, Bapedal Provinsi Jawa Timur) juga memperlihatkan bahwa rata-rata nilai DO Kali Surabaya pada bagian hulu masih relatif lebih baik dibandingkan dengan rata-rata nilai DO di bagian hilir sungai. Sebagian besar rata-rata nilai BOD Kali Surabaya juga masih di bawah standar baku mutu, kecuali pada beberapa bagian sungai yang mendapatkan tekanan aktifitas kegiatan masyarakat cukup besar, khususnya di daerah kawasan industri.

Berdasarkan data yang dikumpulkan dari data Inventarisasi Bidang Penghuni dan Pabrik/Tempat Usaha di Sepanjang Kali Surabaya (Dinas Pengairan Provinsi Jawa Timur), memperlihatkan bahwa jumlah penduduk, jumlah hunian, dan jumlah tempat usaha pada bantaran Kali Surabaya terbesar berada di Kota Surabaya dibanding kota-kota lain yang dilintasi aliran Kali Surabaya. Tercatat ada 35 jenis penggunaan lahan pada bagian ini. Dengan demikian, terlihat bahwa pemanfaatan bantaran dan badan Kali Surabaya oleh masyarakat sudah demikian intensif.

\section{Kesimpulan}

Kesimpulan dari hasil kajian agihan kualitas air Kali Surabaya sebagai berikut:

a. Terjadi penurunan nilai DO dari bagian hulu ke bagian hilir Kali Surabaya, meskipun tidak selalu runtut. Fenomena ini terjadi, baik pada pengukuran di akhir musim hujan maupun pada periode puncak musim kemarau. Dengan demikian dapat dikatakan bahwa ekosistem Kali Surabaya pada bagian hulu masih relatif lebh baik jika dibandingkan dengan di bagian hilir. Kondisi ini dikuatkan oleh hasil pengamatan bahwa, tekanan aktifitas masyarakat di bagian hilir lebih intensif dibandingkan di daerah hulu. 
Ragam jenis penggunaan lahan dan besarnya jumlah masyarakat yang tinggal di bantaran Kali Surabaya bagian hilir adalah bentuk tekanan yang dimaksud.

b. Rata-rata nilai DO hasil pengukuran di puncak musim kemarau menunjukkan nilai lebih besar dibandingkan rata-rata hasil pengukuran di akhir musim hujan.

c. Sementara nilai DO data sekunder lebih besar dibandingkan data hasil pengukuran penelitian. Namun demikian, nilai BOD berlaku sebaliknya.

d. Pengendalian kerusakan ekosistem dapat dilakukan melalui peran serta seluruh masyarakat dalam melakukan kegiatan monitoring kualitas air secara mandiri. Melalui kegiatan monitoring, dapat diketahui kapan dan di bagian mana rehabilitasi ekosistem sungai dapat segera dilakukan. Termasuk melakukan konservasi terhadap bagian aliran sungai yang ekosistemnya masih baik.

\section{Terima Kasih}

Peneliti mengucapkan terima kasih dan penghargaan sebesar-besarnya kepada lembaga Ecoton, yang aktif memberikan edukasi kepada masyarakat penduduk di bantaran Kali Surabaya agar lebih ramah terhadap Sungai. Masyarakat diajak menjaga kelestarian kualitas air sungai melalui kegiatan monitoring dengan metode sederhana. Dalam pengumpulan data penelitian, Ecoton juga senantiasa memberikan dukungannya, termasuk mendampingi saat mengambilan dan pengujian sampel air sungai dan air limbah. Peralatan pengujian lapangan yang dipinjamkan Ecoton, juga sangat membantu terhadap lancarnya pelaksanaan penelitian.

\section{Daftar Pustaka}

Anonim, Data Inventarisasi Bidang Penghuni dan Pabrik/Tempat Usaha di Sepanjang Kali Surabaya. Pelaksanaan Penertiban dan Pendataan Pemanfaatan Bantaran Kali Surabaya Kota Surabaya, Dinas Pengairan Provinsi Jawa Timur.

Anonim, Basis Data Pengelolaan Lingkungan Hidup Tahun 2006, Bapedal Provinsi Jawa Timur

Carolien Kroeze, Silke Gabbert, Nynke Hofstra, dkk, 2016, Global modelling of surface water quality: a multi-pollutant approach, Journal Environmental Sustainability 23, 35-45.

Domenico Patrick, A, Schwartz Franklin, W, 1990, Physical and Chemical Hydrology, John Willey \& Sons, New York.

Edyta Kiedrzyn' ska, Marcin Kiedrzyn'ski, Magdalena
Urbaniak, dkk, 2014, Point sources of nutrient pollution in the lowland river catchment in the context of the Baltic Sea eutrophication, Journal Ecological Engineering 70, 337-348.

Effendie, H, 2003, Telaah Kualitas Air. Bagi Pengelolaan Sumber Daya dan Lingkungan Perairan, Kanisius, Yogyakarta.

Herbert John Bavor, Michael Waters, 2016, Pollutant transformation performance in a peri-urban African wetland system receiving point source effluent and diffuse source pollutant inputs, Wastewater treatment in wetlands: Vol. 7 No. 3-4, 201.

Huub J. Gijzen, 2006, The role of natural systems in urban water management in the City of the Future 3 step strategic approach, Ecohydrology for Implementation of the European Water Framework Directive, Vol.6 No 1-4, 115-122.

Kamran Zeinalzadeha, Elnaz Rezaeib, 2017, Determining spatial and temporal changes of surface water quality using principal component analysis, Journal of Hydrology: Regional Studies 13, 1-10.

Nidhi Gupta, Pankaj Pandey, Jakir Hussain, 2017, Effect of physicochemical and biological parameters on the quality of river water of Narmada, Madhya Pradesh, India, Journal Water Science.

Rafaela Laino-Guanes, Mario Gonza'lez-Espinosa, Neptalı' Ramı'rez-Marcial, dkk, 2016, Human pressure on water quality and water yield in the upper Grijalva river basin in the MexicoGuatemala border, Journal Ecohydrology \& Hydrobiology 95, 1-11.

Richa Bhardwaj, Anshu Gupta, J.K. Garg, 2017, Evaluation of heavy metal contamination using environmetrics and indexing approach for River Yamuna, Delhi stretch, India, Journal Water Science.

TA Ayandiran, OO Fawole, SO Dahunsi, 2017, Water Quality Assessment of Bitumen polluted Oluwa River, South-Western Nigeria, Journal Water Resources and Industry.

Ward, R.C. Robinson, M, 1990, Principles of Hydrology, Mc. Graw Hill International Editions, Lomdon.

Yan Lu, Hongwen Xu, Yuexiang Wang, Yang Yang, 2017, Evaluation of Water Environmental Carrying Capacity of City in Huaihe River Basin Based on the AHP Method: A Case in Huai'an City, Journal Water Resources and Industry. 